\title{
Pre-planning for Service Learning: Creative Strategies through the Lens of Poverty
}

\author{
Anne Mejia-Downs", Julie Gahimer \\ Krannert School of Physical Therapy, University of Indianapolis, Indianapolis, 46227, Indiana, United States
}

Copyright $(2017$ by authors, all rights reserved. Authors agree that this article remains permanently open access under the terms of the Creative Commons Attribution License 4.0 International License

\begin{abstract}
College students involved in service learning are often challenged to consider a deeper appreciation for persons from diverse populations. Many clients in the community organizations we serve are financially disadvantaged. To increase understanding of this common social condition, we implemented pedagogical techniques to bring the realities of poverty into our service-learning course. The purpose of this paper is to describe three different strategies, ranging from pre-packaged programming to self-designed activities, which were used to educate students about the role of poverty in society. These strategies included, 1) a Poverty Simulation which "enables participants to view poverty from different perspectives in an experiential setting", 2) engagement with impoverished clients from a local organization, and 3) group activities using online resources such as videos, a poverty quiz, and games. Students were asked to reflect on their previous views on poverty and how these activities affected them. The aim of these strategies was to encourage students to consider a broad range of perspectives (personal, community, and policy), recognize biases and stereotypes, and link the service learning experience to a broader context in society.
\end{abstract}

Keywords Teaching Strategies, Service Learning, Poverty

\section{Introduction}

Service learning is a pedagogical technique used in higher education to connect students with real world experiences that relate back to course objectives. Dewey, in his text on Experience in Education [1] was one of the first to promote learning through experience, advocating that learners must connect what they are learning in current experiences to past learning experiences as well as see future implications. According to Bringle and Hatcher,[2] service learning is "a credit-bearing, educational experience in which students participate in an organized service activity that meets identified community needs and reflect on the service activity in such a way as to gain further understanding of course content, a broader appreciation of the discipline, and an enhanced sense of civic responsibility."

A variety of disciplines at the University of Indianapolis (UIndy) use the pedagogical technique of service learning. The importance of this educational method is exemplified in the UIndy motto "education for service", and UIndy is one of 115 schools in the nation to receive the Carnegie Foundation for the Advancement of Teaching's Community Engagement Classification. Many faculties include service learning projects in their courses while some faculty lead service learning trips, locally, nationally and internationally. For example, medical missions in Central America as well as projects in Appalachia have commenced over the past several years. Much of this work is conducted through the university's Center for Service Learning and Community Engagement. The center serves as a resource for service learning initiatives that are conducted by the numerous academic departments. The UIndy "Vision 2030" builds upon the institution's rich history to create an environment that champions leadership and service.

Poverty has been studied on a global level by calculating a poverty headcount ratio: a poverty line is set and the number of people living with incomes or consumption levels below that poverty line is counted. A person living on less than 1.90 international dollars (int.-\$) per day is considered to be in extreme poverty, according to the World Bank, the institution that sets the International Poverty Line. There are also alternative ways for measuring welfare including life satisfaction indexes, basic needs, and capabilities such as access to education and basic human rights [3].

College students involved in service learning are often challenged to develop a deeper appreciation for persons from diverse populations. Many clients in the community organizations we serve are financially disadvantaged. To increase understanding of this common social condition, we implemented pedagogical techniques to bring the realities of poverty into our service-learning course.

The purpose of this paper is to describe three different 
educational strategies, ranging from pre-packaged programming to self-designed activities that were used to educate our students about the role of poverty in society.

\section{Materials and Methods}

The aim of the following activities was to encourage students to consider a broad range of perspectives (personal, community, and policy), recognize biases and stereotypes, and link the service learning experience to a broader context in society. When it was available to us, we used the pre-packaged poverty simulation which was conducted by an outside group for a fee. When this was not available, we devised two alternate, less expensive activities.

Following each of the poverty activities, students were asked to reflect and answer the following questions:

1. What were your thoughts about poverty before you participated in the activity?

2. How did those thoughts change as a result of the activity?

Students were asked to pay attention to and demonstrate respect for others' viewpoints, demonstrate the ability to link the experiences to a broader context (classroom material, past experiences, outside resources, current issues), and demonstrate expanded or reconsidered personal views.

\subsection{Poverty Simulation}

The Community Action Poverty Simulation $(\mathbb{C}$, developed by the Missouri Association for Community Action [4] is a copyrighted tool that "enables participants to view poverty from different angles in an experiential setting." It was developed to raise awareness about different aspects of poverty that can lead to discussions about the potential for change in local communities. Over 1,000 organizations worldwide have used this unique tool including nonprofit organizations, educational institutions, and community action teams [5].

This guided experience exposed participants to the realities of poverty, including challenges of navigating the complex world of government services and other essential service providers. During the simulation, participants assumed pre-designed roles of different family members facing poverty. The task for each family was to provide basic necessities and shelter, while balancing the realities of daily life. Volunteers from the Bridges/Circles ${ }^{\circledR}$ Coalition of Greater Indianapolis, an anti-poverty initiative, staffed the simulation and a trained facilitator managed the event.

Fifty to 75 participants assumed the roles of up to 26 different families facing poverty. Participant's roles included the following descriptions:

- "A single parent with limited resources and no transportation must find a way to get to work and get their child to daycare."
- "An elderly person must find a way to pay for both utilities and medication."

- "A young adult must care for siblings while their parent is incarcerated."

- "An elderly couple must raise their grandchildren and deal with their own health and employment issues." (http://www.povertysimulation.net/about/\#what)

The task of the "families" was to visit necessary social services and community sites (e.g. employer, school, grocery, bank, mortgage, pawn shop, police station, quick cash, daycare center) to provide for family needs during the course of four 15-minute "weeks".

The simulation lasted two to three hours, and consisted of an introduction and briefing, the actual simulation exercise, and a debriefing period for participants and volunteers to share reactions and experiences. The ultimate goal of the simulation was to acknowledge stereotypes and allow students to experience empathy for people who have limited resources. They also were challenged to recognize the interconnectedness and complexity of poverty.

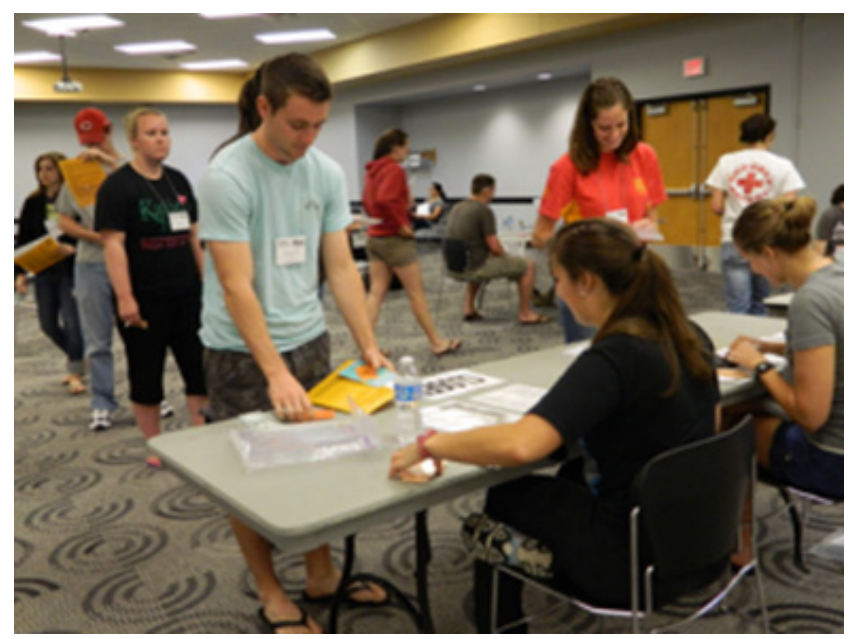

Figure 1. Poverty Simulation

\subsection{Engaging with Community Members}

The second learning strategy was to invite into the classroom a trained facilitator and clients from Circles of Support, a program that assists clients with limited resources to become self-sufficient by engaging community support. Four activities were presented:

1. Fifteen Candy Budget: Students worked in pairs to distribute a budget (represented by candies) among housing needs, utilities, food, transportation, and other necessities.[6] Each team engaged in a role play in which their family consisted of a married couple with two children, one parent working full-time and the other working two part-time jobs - both at minimum wage. The family budget was limited requiring difficult decisions to be made.

2. Cliff Effect: Students were challenged with the common misperception that individuals in poverty "just 
don't want to work hard and get ahead". The class had a discussion about the "cliff effect", which can occur when a person who is in poverty has an increase in income, which results in the loss of other benefits, such as child care subsidies or medical benefits and is a barrier to self-sufficiency. [7] For example, income determines eligibility for social support benefits, such as Supplemental Nutrition Assistance Program (SNAP), and Child Care Development Fund (CCDF). [8] When income increases with a better job or a raise, these benefits may be lost. The "cliff effect" results in a lack of incentive, as people are working harder, but are worse off financially.

3. Laundry Basket Activity: Students were asked to imagine someone who has very few resources: a low-paying job, no family nearby, trying to stay off welfare, and no good family role model. The parent was a single mother with two children - a daughter in elementary school and a son who was a toddler. She was overwhelmed by all of life's struggles, and was having trouble keeping up with life's demands. A student was chosen to represent this person and was handed household items that represented the daily tasks for which she was responsible. These included: cooking meals for her family (pan), taking her daughter to soccer (soccer ball), taking a math course to finish her high school diploma (textbook), reading to her toddler (picture book), doing laundry at the laundromat (laundry basket), cleaning house (broom), home repair (duct tape), and car maintenance (motor oil). The student had difficulty physically holding onto all the items, which represented keeping up with multiple responsibilities. The remaining students were asked to consider ways in which the community could support this individual by decreasing her burden. The activity concluded with other students volunteering to help her with these activities to "take a load off of her" and removed the household items one by one, to allow her to have a better work/life balance.

4. Personal Stories of Poverty: Clients from Circles of Support ${ }^{\circledR}$ shared their personal stories of "bridging out of poverty". Many discussed tough choices they made with a limited income. They shared examples of the "cliff effect" in their lives, and how individuals from Circles of Support ${ }^{\circledR}$ assisted. Students then shared how these stories impacted their view of poverty and the working poor.

\subsection{Using Online Resources}

The third learning strategy was to provide a "poverty experience" using online resources. These resources were identified using Open Educational Resources (OER), which are free and accessible, non-copyrighted media resources for teaching. OER offers "opportunities for systemic change in teaching and learning content through engaging educators in new participatory processes and effective technologies for engaging with learning."[9] OER resources we chose from included: case studies, interactive activities, readings, lectures, lesson plans, and data sets, in various media formats. Another resource used was MERLOT II (Multimedia Educational Resource for Learning and Online Teaching) from California State University, a "curated collection of free and open online teaching, learning, and faculty development services contributed and used by an international education community." [10]

The students completed the following activities:

1. Poverty Quiz: Students were asked to complete a ten-item quiz: What do you know about poverty in America? [11] The quiz consisted of questions related to the number of Americans on food stamps, unemployment rate for African-Americans, income by class and race, the number of people living in poverty, and the child poverty rate in America.

2. Spent Activity: This interactive website challenged the students to decide how they would spend their budget after a job loss. [12] They had to decide how to allocate their funds toward housing, food, child care, and transportation.

3. One Dollar A Day: Students were shown a 2013 video about four young men who spent two months in rural Guatemala, with the goal of living on one dollar a day.[13] In addition, students viewed other videos on poverty from a list provided to them, e.g. PBS stories, and TED Talks. In small groups, students discussed aspects related to their newly acquired views on poverty.

4. Six Hats Discussion: This way of thinking about an issue has been described by author Edward de Bono, and can be used for any topic of discussion.[14] For this activity, students were asked to wear hats to class. Each person was assigned a colored tag to pin on their hat. They were then placed in small groups with each color represented and asked to portray the colors' attributes during a discussion of poverty. Students utilized the information gathered from the previously described online activities to guide their discussion. Colors and attributes with examples of each are as follows:

- Red: feelings, emotions, rage ("poverty is terrible, no one cares")

- Green: new ideas, creativity, growth ("better ideas for affordable housing")

- Yellow: positive, optimistic ("some states are doing a great job")

- Black: logical, negative, gloomy ("there's nothing we can do about this")

- White: data, facts, information ("the poverty stats are worse this year")

- Blue: controls the group process, organization, summarize ("so here are the major points we've discussed") 


\section{Results}

Students' perspectives about poverty were challenged with these educational strategies. Comments from students, related to each of the strategies, included the following:

\section{Poverty Simulation}

- "My stereotype before this activity has changed in that I know how hard these individuals have to work on a daily basis to provide for their family... I believe this activity has given me a different perspective into the life of poverty. I am inspired to help in the community by giving assistance to increasing resources available to those trying to rise above poverty."

- "The experience did an incredible job at giving me a taste of the stresses people in poverty face daily. I feared for the safety of my 'family'... I truly felt burdened by having to take my disabled 'father' with me everywhere. I cried when I saw my 'husband' being arrested...I had anxiety over how we should prioritize our money. I questioned if I should buy food or pay my mortgage."

\section{Engaging with Community Members}

- "Having three guests that have been struggling with poverty for most of their lives was eye-opening...In the past few years, my view of poverty has been slowly evolving...I have come to realize that many people in unfortunate economic situations were born into a vicious cycle that can be difficult to break out of. It can be easy to sit back and judge an impoverished individual...However, people go through some unimaginable things and unless we have walked in their shoes, we have no right to judge the decisions they have made in life. I've always had a safe home, three meals a day, little stress, great health, and incredible support from family and friends."

- "The stories that were talked about in class made it clear that there are so many different routes to poverty. There are many times that society blames the individual, but it is not always completely in their control. For instance, sexual abuse as a child that goes unchecked and leads to substance abuse as one of our guests shared in his story was not a situation of his making...children from single parent households may never be able to break out of the cycle of poverty. Expecting people to simply realize how to pull themselves up by their bootstraps is unreasonable."

\section{Using Online Resources}

- "The poverty activity really opened my eyes to the life of poverty. The quiz that we took really showed me how much I do not know about poverty in our nation. The next activity we did of Spent was very eye opening to how not having money really causes conflict of morals and taking care of your family. For us, it was just an activity, but this is a simulation of some people's lives and I cannot even imagine living a life such as that. After this activity, we watched the TED talk on "Living on a Dollar a Day." I did not know that so many people around the world live on a dollar amount each day."

\section{Discussion}

Students who participated in service learning often engaged with populations different from themselves. Many of these populations included people who lived in poverty, and students were challenged to internalize the circumstances of these individuals. This paper is intended to provide educators with a variety of strategies and tools to actively engage students in thoughtful consideration of the effects of poverty. These strategies were designed to broaden students' personal and societal perspectives about the circumstances surrounding poverty.

The advantage of the Poverty Simulation was that it provided students with an experience in all three learning domains. The cognitive domain was engaged as students considered how to negotiate the barriers in the system, moving from "home" to each of the community and social service sites made use of the psychomotor domain, and the affective domain was engaged as the students experienced a variety of feelings throughout the simulation. As an educator, this strategy took a small amount of effort, because the event was pre-organized and facilitated by an experienced individual. The disadvantages of this approach were the large physical space required to conduct the simulation as well as sufficient funds.

A positive aspect of engaging with community members who have experienced poverty is that it allows the students to develop empathy for this social situation. Together with the laundry basket activity and the discussion of the "cliff effect", students learn how poverty affects multiple aspects of life. The downside of this strategy is the increased amount of planning by the educator, and it also required a skilled moderator for a meaningful discussion between community members and students. It is preferable to provide an incentive for the community members' participation, so some level of funding would be necessary.

The advantage of the strategy of using online resources is that the educator is fully in control of the structure of the activity. It is also a suitable activity for a small group or a large number of students. In addition, the only financial cost is the ubiquitous presence of internet access. The challenge for the educator is the amount of time and effort required well in advance of the activity to identify appropriate resources and plan the activity. Students must be fully engaged and willing to participate in all aspects of the process for a successful outcome.

\section{Conclusions}

Our intention was to broaden students' personal and 
societal perspectives prior to their engagement in a service learning experience. We described three strategies, a simulation, community interaction, and online collection of resources and activities, to educate students about poverty. Through student reflection, we saw how students' perspectives about poverty were reconsidered. As a result of these immersive activities, students were able to consider a broad range of personal, community, and policy perspectives, recognize personal biases and stereotypes, and most importantly, link the service learning experience to a broader context in society.

\section{Acknowledgements}

We are grateful to the facilitator, the community members, and students who participated in these activities.

\section{REFERENCES}

[1] Dewey, J. Experience and Education. New York: Free Press, 2015. Kappa Delta Pi lecture series. (C)1938.

[2] Bringle, RG, Hatcher JA. "Implementing Service Learning in Higher Education” (1996). Higher Education. Paper 186. Online available:

http://digitalcommons.unomaha.edu/cgi/viewcontent.cgi?arti cle $=1188 \&$ context $=$ slcehighered

[3] Center for American Progress. Online available: https://ourworldindata.org/extreme-poverty/

[4] Missouri Community Action. Online available: http://www.c ommunityaction.org/

[5] Community Action Poverty Simulation. Online available: http://www.povertysimulation.net/about/\#what

[6] United Way of Greater New Haven. Online available: https://www.uwgnh.org/post/making-choices-activity

[7] PBS News Hour. Online available: http://www.pbs.org/newshour/rundown/when-getting-a-raise -means-losing-ground-for-low-income-families/

[8] Indiana Institute for Working Families. Online Available: http://www.incap.org/cliffeffect.html\#.WWaIO1G1vIU

[9] OER Commons and Open Education. Online available: https://www.oercommons.org/about

[10] Mutimedia Educational Resource for Learning and Online Teaching. MERLOT II. Online available: https://www.merlo t.org/

[11] Marketplace. American Public Media. Wealth and Poverty. October 29, 2012. Online available: http: //www.marketplace.org/topics/wealth-poverty/quiz-what-doyou-know-about-poverty-america

[12] Urban Ministries of Durham. Online available: $\mathrm{http}: / /$ playspent.org/

[13] One Dollar a Day. Online available: https://www.youtube.com/watch?v=RCT5HsUi7VE

[14] De Bono Consulting. Online available: http://debonoconsulting.com/training-courses/six-thinking-h ats/?gclid=CLaesMnL7dQCFQqtaQodGS0O3A 